\title{
COMPARISON OF THE ADSORBENT EFFICIENCY OF DIFFERENT TYPES OF GRANULATED ACTIVATED CHARCOAL
}

\author{
${ }^{1}$ Ivana MARKO* ${ }^{2}$ Štefan STANKO, ${ }^{3}$ Réka CSICSAIOVÁ \\ 1,2,3 Department of Sanitary and Environmental Engineering, Faculty of Civil Engineering \\ Slovak University of Technology in Bratislava, Radlinského 11, 81005 Bratislava, Slovakia \\ e-mail: ${ }^{1}$ ivana.marko@stuba.sk, ${ }^{2}$ stanko.stefan@stuba.sk, ${ }^{3}$ reka.csicsaiova@stuba.sk
}

Received 29 December 2018; accepted 8 April 2019

\begin{abstract}
This paper is about comparing the effectiveness of the sorbent materials of granulated activated carbon in removing of bromates from drinking water. The limit value $\left(10 \mu \mathrm{g}^{-1}\right)$ of bromates in the drinking water was stated by World Health Organization. In order to insure the reduced concentration of bromates in the drinking water, an experiment was performed using the batch test. In this experiment different types of sorbent materials with different properties were testing. Based on batch test were measured the parameters like the immediate adsorption capacity, the adsorption efficiency, and the concentration of bromates after the adsorption were measured at the evaluated time.
\end{abstract}

Keywords: Adsorption, Batch test, Bromates, Granulated activated carbon, Sorbent materials

\section{Introduction}

One of the main problems of water companies is to provide the healthy and harmless drinking water. The quality of the drinking water source is constantly deteriorating, especially due to anthropogenic pollution of the environment, discharging hazardous substances in water or soil. Based on statistical assumptions, the situation will only deteriorate in the future. Demands for drinking water will progressively increase, while drinking water supplies will reduce.

In other to ensure harmless drinking water, the raw water must treated by various technological processes. Filtration is one of the most extensive processes in which water

${ }^{*}$ Corresponding Author 
passing through porous environment, called as sorbent material. Sorbents are insoluble materials or mixtures of several types of materials, which can quickly and effectively adsorb organic or inorganic substances from water. Removal of pollutants from the drinking water using the sorbent materials can be realized through adsorption or absorption processes [1]. The difference between these two processes is that adsorption is ability of substances to bind other solid to other surface and absorption is process of dissolving or adsorbing the gas or liquid in solid materials [1], [2]. Adsorption has a great significance in water treatment, especially in drinking water treatment. It is a complicated process used for removal of organic pollutants from heavily polluted water. As important substance in adsorption process is adsorbed, also called as sorbent material, on which surface adsorption is going on.

Sorbent materials are frequently used as additive in emergency situations to adsorb leaked substances (oil, fats, chemical liquids) from water or solid base. They are appropriate as a preventive protection in production and operating facilities with the assumption of leakage of hazardous chemicals. In water management, they are often used for decontamination in oil accidents, for waste water and drinking water treatment. Sorbent materials are frequently used as an additive to provide the sensory properties of water states by government. They can be used to remove surplus chlorine, fluorine, bromine, and other hygienically harmful substances. Also, sorbent is very often applied in heavy metals removal [3]. The great advantage of sorption materials is their tensile strength after sorption and the possibility of regeneration, while preserving their original adsorption capacity [2], [4].

Due to high absorbent efficiency sorbent materials are often used in reduction bromates from drinking water [5], [6]. In many cases, Granulated Active Carbon (GAC) was used as a sorbent material and was found to have a good sorbent property in removing bromates [7]. Because of excellent adsorbent efficiently activated carbon has ability to absorb bromates $\left(\mathrm{BrO}_{3}^{-}\right)$, reduce to hypobrominte $\left(\mathrm{BrO}^{-}\right)$and in the end reduce to bromine $\left(\mathrm{Br}^{-}\right)$[6].

\section{Properties of sorbent materials}

Activated carbon is a crude form of graphite, which is characterized by high adsorbent efficiency, up to $90 \%$ [1], [2]. It is non-polar adsorbent that mainly adsorb non-polar organic substances or non-electrolytes. The adsorbent properties of activated carbon depend of the methods of preparation. Activated carbon can be of mineral or organic origin, produced by thermal or thermo-chemical treatment. The substances, from which it is made, have high carbon content for instance: coal, coconut shells, wood, bamboo, willow peat and other materials from carbonaceous source. The large influence on the physical and chemical properties of the activated charcoal has materials, from which it is made, and time and temperature of the activation process. Because of his specific structure formed by imperfect graphite plates, activated carbon is having a large surface area range from 600 to $1500 \mathrm{~m}^{2} \cdot \mathrm{g}^{-1}$ [1], [2].

In this experiment four types of GAC were used, from two different producers: Cabot Corporation and European Operations of Calgon Carbon Corporation. These sorbents were selected based on their specification and adsorbent efficiency in other 
researches [6]. The general characteristic of selected sorbent materials of granulated activated carbon, including composition, colour, iodine number, particle size, density, hardness and other manufacture specifications are illustrated in Table I [7]-[10].

Table I

General characteristic of activated coal

\begin{tabular}{|c|c|c|c|c|c|}
\hline & Unit & $\begin{array}{c}\text { GAC } \\
\text { Filtrasorb } \\
\text { F400 }\end{array}$ & $\begin{array}{c}\text { GAC } \\
\text { Filtrasorb } \\
\text { F100 }\end{array}$ & $\begin{array}{c}\text { GAC Norit } \\
1240 \mathrm{~W}\end{array}$ & $\begin{array}{c}\text { GAC Norit } \\
830 \mathrm{~W}\end{array}$ \\
\hline Composition & - & $\begin{array}{l}\text { bituminous } \\
\text { coal }\end{array}$ & $\begin{array}{l}\text { bituminous } \\
\text { coal }\end{array}$ & coconut shell & $\begin{array}{l}\text { selected } \\
\text { grades of } \\
\text { coal }\end{array}$ \\
\hline Color & - & black & black & black & black \\
\hline Iodine number & $\mathrm{mg} \cdot \mathrm{g}^{-1}$ & 1000 & 850 & 975 & 950 \\
\hline Particle size & $\mathrm{mm}$ & $0.55-0.75$ & $0.59-2.30$ & $0.42-1.70$ & $0.60-2.36$ \\
\hline $\begin{array}{l}\text { Mean particle } \\
\text { size }\end{array}$ & $\mathrm{mm}$ & $0.6-0.7$ & $0.8-1.0$ & $0.6-0.7$ & 0.9 \\
\hline Density & $\mathrm{kg} \cdot \mathrm{m}^{3}$ & 450 & 500 & 420 & 433 \\
\hline $\begin{array}{c}\text { Total surface } \\
\text { area }\end{array}$ & $\mathrm{m}^{2} \cdot \mathrm{g}$ & 1050 & 850 & 1100 & 1150 \\
\hline $\begin{array}{l}\text { Ball-Pan } \\
\text { hardness }\end{array}$ & - & 95 & 95 & 97 & 95 \\
\hline
\end{tabular}

\subsection{Granulated activated coal Norit $1240 \mathrm{~W}$ and Norit $830 \mathrm{~W}$}

GAC Norit $1240 \mathrm{~W}$ and Norit $830 \mathrm{~W}$ are produced by physical treatment by steam activation in Cabot Corporation from USA in Boston. Difference between these sorbents materials is that Norit $1240 \mathrm{~W}$ is made from coconut shell [6], and Norit $830 \mathrm{~W}$ from selected grades of coal [8]. Both sorbent materials have well adsorption properties. They can be used for removal of natural, and synthetic organic pollutants and suspended solids from surface, and groundwater sources, as well as disinfection by-products that are formed during the water treatment process. Also, these sorbent materials can be applied in the removal of contaminants like, perfluorooctane sulfonate and other polyfluoroalkyl substances from the drinking water. GAC Norit $830 \mathrm{~W}$ is specially made for the purification of gas treated liquids [7], [8].

\subsection{Granulated Activated Coal Filtrasorb F 400 and GAC Filtrasorb F 100}

GAC Filtrasorb F 400 and GAC Filtrasorb F 100 are sorbent materials produced by European Operations of Calgon Carbon Corporation from Boston. They are made by steam activation of selected grades of bituminous coal [9], [10]. Bitumen coal used in production is firstly pulverised and then agglomerated. The bitumen base ensures the good physical and chemical properties of Filtrasorb. These sorbent materials are efficient in improving the quality of the drinking water. The Filtrasorb F 400 is usually used for removing organic substance, for instance: pesticide and micro-pollutants, and disinfection by-products. The Filtrasorb F 100 has the resemble properties as Filtrasorb F 400, but different application. It can be effective in improving organoleptic properties 
of drinking water, for removing lower concentration of organic substances, and chlorinated hydrocarbon. Both of sorbent materials are usually used in removing substances, such as: chlorine, chloro-dioxide and ozone [9], [10].

\section{Experiment}

The aim of this work is to compare adsorbent effectiveness of four types of granulated activated coal in bromate decrease from drinking water. This work is continuation of the experiment, where seven different types of sorbent materials were tested by batch-test, and in which it was found that zeolite and active carbon has high adsorbent efficiency [5].

Bromates are classified as toxic substances that in small concentration can cause some health problems, for instance: vomiting, abdominal pain, diahrea etc. [11]. According to research of International Agency for Research on Cancer, bromates can cause a human carcinogen. Based on this statements and recommendation of the US Environmental Protection Agency (EPA), the World Health Organization (WHO) set the limit value of bromates in drinking water to $10.0 \mu \mathrm{g} \cdot \mathrm{l}^{-1}$ [12]. In Slovak Republic the limit value is determined by Decree of the Ministry of Health No. 247/2017 Coll. and is complied with recommendation WHO and EPA [12], [13].

\subsection{Method of experiment}

The experiment was performed in laboratory conditions of the Slovak University of Technology (STU) using the batch-test. As model water, raw water was used with initial concentration of bromates $41.2 \mu \mathrm{g} \cdot \mathrm{l}^{-1}$. During the experiment, the effectiveness of sorbent materials listed in Table I. (GAC Norit 1240W, GAC Norit 830W, GAC Filtrasorb F400, GAC Filtrasorb F100) was monitored. Sorbent materials used in the laboratory test are shown in Fig 1.
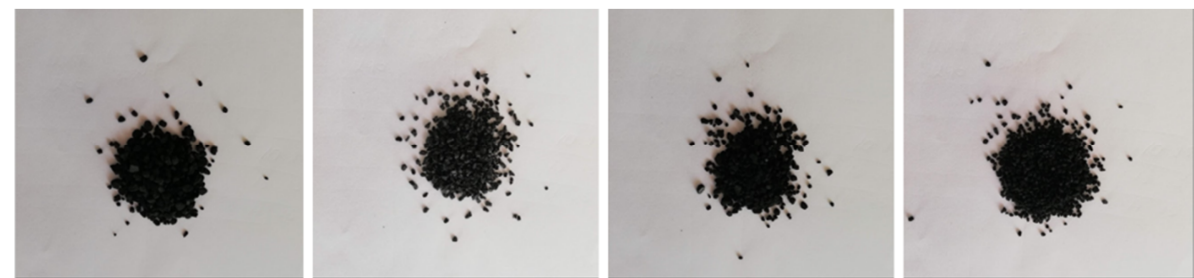

Fig. 1. Selected sorbent materials: GAC Filtrasorb F100, GAC Norit 1240W, GAC Norit 830W, GAC Filtrasorb F400

The laboratory test was divided into few parts. First, bottles of $200 \mathrm{ml}$ of model water were prepared, in which $2.0 \mathrm{~g}$ of selected sorbent materials were added. Together there were twelve samples with sorbent materials and one sample with model water as is shown on Fig 2. The contact time of sorbent materials with model water was one hour, four hours and eight hours. After one hour, from first four samples with different sorption material $100 \mathrm{ml}$ of water was taken out. The procedure was the same after four 
hours and eight hours for the rest model samples. In order to stabilize bromates, EthyleneDiAmine (EDA) was added $(0.1 \mathrm{ml}$ into $100 \mathrm{ml}$ of the sample) into the samples.

Analysis of model samples was performed in the laboratory conditions of the West Slovak Water Company in Bratislava. The effectiveness of the granulated activated carbon in decreased concentration of bromates from the drinking water was monitored by the device 850 Professional IC Anion. This device is used for ion chromatographic determination of anions or polar substances with sequential suppression [14].

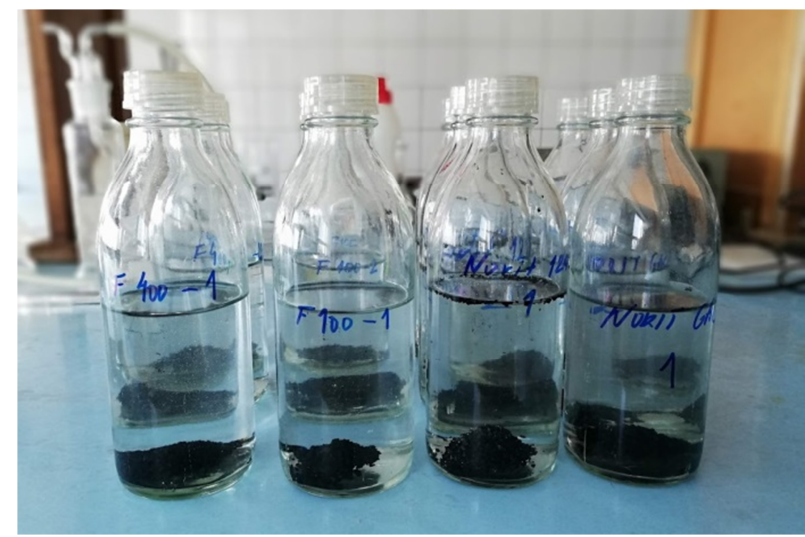

Fig. 2. Samples of model water, with sorbent materials

\section{Results and discussion}

In laboratory test, the effectiveness of individual sorption materials in bromates removal was monitored. The initial concentration of bromates was $41.2 \mu \mathrm{g} \cdot \mathrm{l}^{-1}$ and the contact time of model water with selected sorption materials was one hour, four hours and eight hours. Measured values from batch-test are listed in Table II that demonstrates a concentration of bromates in particular times for different types of sorbent materials.

\section{Table II}

Values measured by the device 850 Professional IC Anion

\begin{tabular}{|l|l|l|l|l|c|}
\hline \multirow{2}{*}{ No. } & Material & 0 hour & 1 hour & 4 hours & 8 hours \\
\cline { 3 - 6 } & & \multicolumn{4}{|c|}{ Bromates $\left(\mu \mathrm{g} \cdot 1^{-1}\right)$} \\
\hline 1 & GAC Norit 1240W $(0.42-1.70 \mathrm{~mm})$ & 41.20 & 34.40 & 29.90 & 22.80 \\
2 & GAU Norit 830W $(0.60-2.36 \mathrm{~mm})$ & 41.20 & 37.50 & 30.40 & 24.70 \\
3 & GAU Filtrasorb F400 $(0.55-0.75 \mathrm{~mm})$ & 41.20 & 36.00 & 31.10 & 25.70 \\
4 & GAU Filtrasorb F100 $(0.59-2.30 \mathrm{~mm})$ & 41.20 & 33.50 & 29.30 & 26.50 \\
\hline
\end{tabular}


Based on the measured value, the efficiency of bromates removal - $\eta(\%)$ and immediate adsorption capacity $-a_{t}\left(\mathrm{mg} \cdot \mathrm{g}^{-1}\right)$, was calculated by the following equation (1) and (2):

$$
\begin{aligned}
& a_{t}=\frac{\left(c_{O}-c_{m}\right) V}{m}\left(\mu \mathrm{g} \cdot \mathrm{g}^{-1}\right), \\
& \eta=\frac{\left(c_{O}-c_{m}\right) 100}{c_{O}}(\%),
\end{aligned}
$$

where $a_{t}$ is the immediate adsorption capacity $\left(\mu \mathrm{g} \cdot \mathrm{g}^{-1}\right) ; \eta$ is the adsorption efficiency $(\%) ; c_{o}$ is the concentration of bromates before the adsorption $\left(\mu \mathrm{g} \cdot 1^{-1}\right) ; c_{m}$ is the concentration of bromates after the adsorption at the time $\left(\mu \mathrm{g} \cdot \mathrm{l}^{-1}\right) ; V$ is the volume of model water solution $(0.2 \mathrm{l}) ; \mathrm{m}$ is the weight of sorption material $(2.0 \mathrm{~g})$ [1].

The data calculated by Eq. (1) and (2) are listed in Table III, which shows the contact time of model water with sorbent, concentration of bromates before adsorption, immediate adsorbent capacity and adsorbent efficiency.

\section{Table III}

Values calculate by formula (1) (2)

\begin{tabular}{|c|c|c|c|c|c|}
\hline Value & Unit & \multicolumn{4}{|c|}{ GAC Norit 1240W } \\
\hline$t$ & {$[\mathrm{hour}]$} & 0 & 1 & 4 & 8 \\
$c_{m}$ & {$\left[\mu \mathrm{g} \cdot \mathrm{l}^{-1}\right]$} & 41.20 & 34.40 & 29.90 & 22.80 \\
$a_{t}$ & {$\left[\mu{\left.\mathrm{g} \cdot \mathrm{g}^{-1}\right]}^{-1}\right.$} & - & 0.68 & 1.13 & 1.84 \\
$\eta$ & {$[\%]$} & 0.00 & 16.50 & 27.43 & 44.66 \\
\hline Value & Unit & \multicolumn{4}{|c|}{ GAC Norit $830 \mathrm{~W}$} \\
\hline$t$ & {$[\mathrm{hour}]$} & 0 & 1 & 4 & 8 \\
$c_{m}$ & {$\left[\mu \mathrm{g} \cdot 1^{-1}\right]$} & 41.20 & 37.50 & 30.40 & 24.70 \\
$a_{t}$ & {$\left[\mu \mathrm{g} \cdot \mathrm{g}^{-1}\right]$} & - & 0.37 & 1.08 & 1.65 \\
$\eta$ & {$[\%]$} & 0.00 & 8.98 & 26.21 & 40.05 \\
\hline Value & Unit & \multicolumn{5}{|c|}{ GAC Filtrasorb F400 } \\
\hline$t$ & {$[\mathrm{hour}]$} & 0 & 1 & 4 & 8 \\
$c_{m}$ & {$\left[\mu \mathrm{g} \cdot 1^{-1}\right]$} & 41.20 & 36.00 & 31.10 & 25.70 \\
$a_{t}$ & {$\left[\mu \mathrm{g} \cdot \mathrm{g}^{-1}\right]$} & - & 0.52 & 1.01 & 1.55 \\
$\eta$ & {$[\%]$} & 0.00 & 12.62 & 24.51 & 37.62 \\
\hline Value & Unit & \multicolumn{5}{|c|}{ GAC Filtrasorb F100 } \\
\hline$t$ & {$[\mathrm{hour}]$} & 0 & 1 & 4 & 8 \\
$c_{m}$ & {$\left[\mu \mathrm{g} \cdot \mathrm{l}^{-1}\right]$} & 41.20 & 33.50 & 29.30 & 26.50 \\
$a_{t}$ & {$\left[\mu \mathrm{g} \cdot \mathrm{g}^{-1}\right]$} & - & 0.77 & 1.19 & 1.47 \\
$\eta$ & {$[\%]$} & 0.00 & 18.69 & 28.88 & 35.68 \\
\hline
\end{tabular}

Pollack Periodica 14, 2019, 3 
From the calculated data that are listed in Table III, graphs were designed for particular parameters. Collected data are illustrated in Fig. 3, Fig. 4 and Fig. 5.

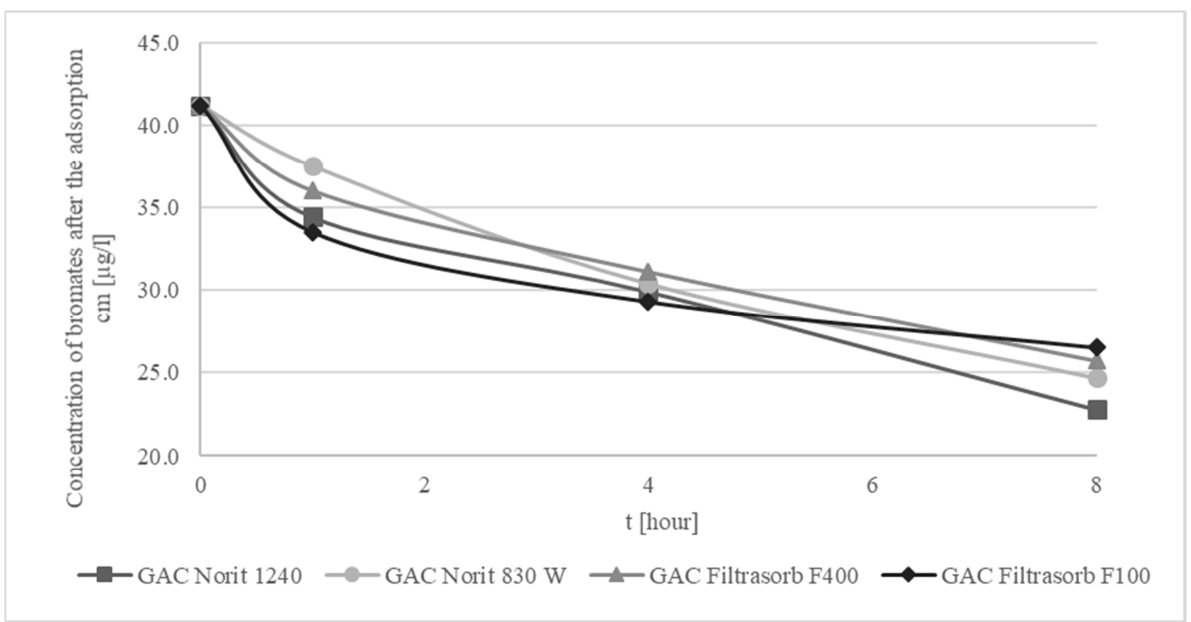

Fig. 3. Course of concentration of bromates after adsorption at the time, with initial concentration of bromates $41.2 \mu \mathrm{g} \cdot \mathrm{l}^{-1}$

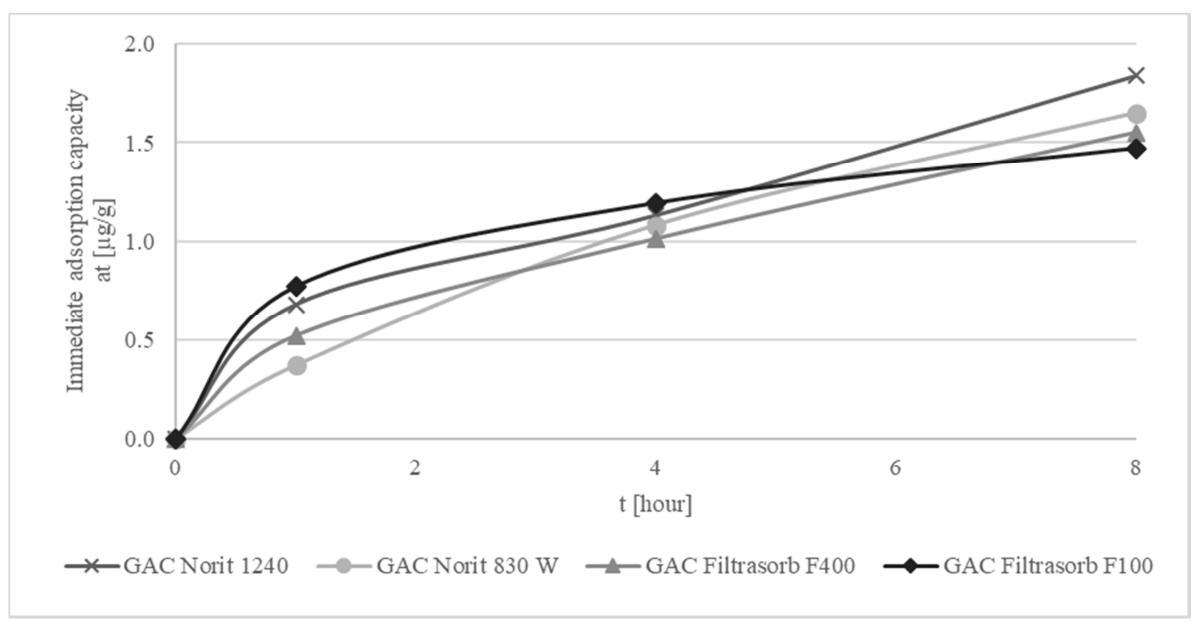

Fig. 4. Course of immediate adsorbent capacity at the time, with initial concentration of bromates $41.2 \mu \mathrm{g} \cdot \mathrm{l}^{-1}$

Fig. 3 shows the decreased concentration of bromates after the adsorption at the particular time, with initial concentration of bromates $41.2 \mu \mathrm{g} \cdot \mathrm{l}^{-1}$, and Fig. 4 shows the immediate adsorbent capacity of selected sorbent materials at the time. Based on results it can be stated, that none of selected sorbent materials (GAC Norit 1240W, GAC Norit 830W, GAC Filtrasorb F400 and GAC Filtrasorb F100) was able to reduce the 
concentration of bromates below the limit value stated be MH SR. No. 247/2017 Coll. $\left(10.0 \mu \mathrm{g} \cdot \mathrm{l}^{-1}\right)$ [12]. The reduced concentration of bromates after the eight hours of contact time was relatively low, ranging from $22.80 \mu \mathrm{g} \cdot \mathrm{l}^{-1}$ to $26.58 \mu \mathrm{g} \cdot \mathrm{l}^{-1}$. Immediately adsorbent capacity of sorbent materials after four hours was approximately the same (about $1.10 \mu \mathrm{g} \cdot \mathrm{l}^{-1}$ ), but after eight hours the best adsorbent capacity has the GAC Norit $1240 \mathrm{~W}\left(1.84 \mu \mathrm{g} \cdot \mathrm{l}^{-1}\right)$. The highest decrease of concentration of bromates has sorbent material GAC Norit $1240 \mathrm{~W}$, which achieved a reduction of bromates almost $45.0 \%$ (Fig. 5.) of total amount of bromates in model water (100.0\%).

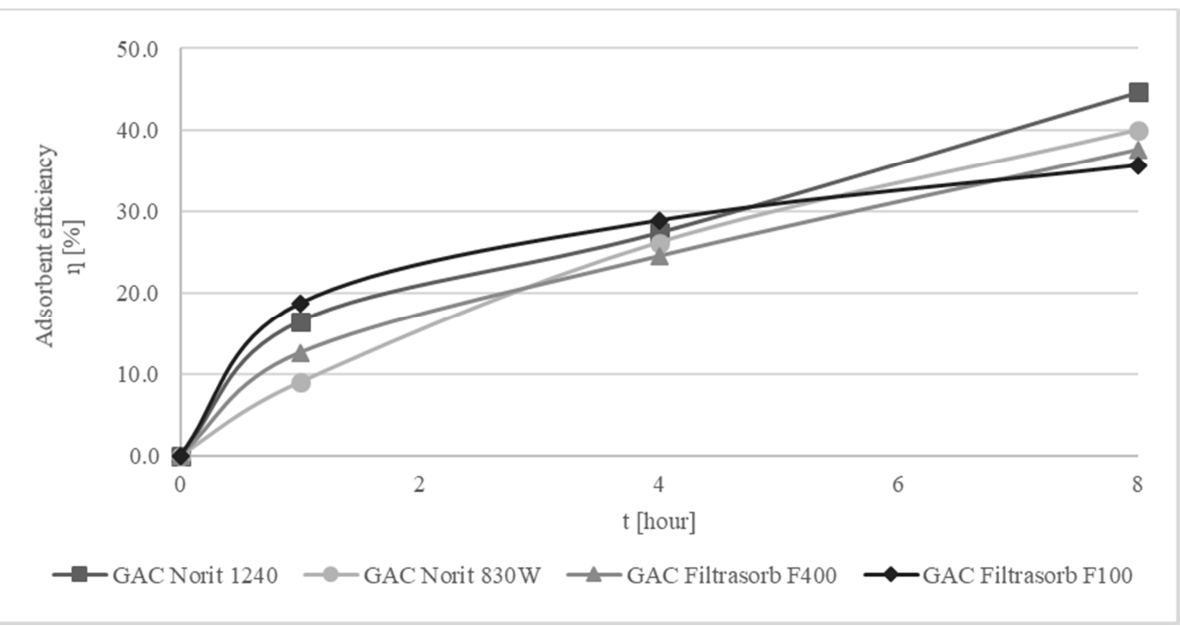

Fig. 5. Course of adsorbent efficiency at the time, with initial concentration of bromates $41.2 \mu \mathrm{g} \cdot \mathrm{l}^{-1^{\prime}}$

The adsorbent efficiency of other sorbent materials after eight hours of contact time was approximately the same, ranging from $36.0 \%$ to $40.0 \%$. The sorbent material with lowest effect was GAC Filtrasorb F100, which was able to decrease concentration of bromates after eight hours about $35.68 \%$.

\section{Conclusion}

The aim of the experiment was to compare adsorbent effectiveness of granulated activated carbon in decreased concentration of bromates from the drinking water of limited value stated by Decree of the Ministry of Health of the SR. No. 247/2017 Coll. The efficiency of sorbent materials was monitored in laboratory by device 850 Professional IC Anion. The experiment was performed by batch-test, on which basis adsorbent efficiency and adsorbent capacity of sorbent materials were determined.

The calculated data of the present study demonstrated, that use of granulated activated carbon gave good results in bromates decrease from the drinking water. In present experiment the sorption material with high adsorbent efficiency was GAC Norit $1240 \mathrm{~W}$, which achieved a bromate reduction about $44.66 \%$, but not enough to decrease 
below the limited value. To achieve the desired bromates decreasing, it is necessary to increase the contact time of sorption materials with model water or the weight of sorption material. Based on these results, experiment will be continued, with focus on a dynamic where filter columns will be used.

\section{Acknowledgements}

This article was created with the support of the Ministry of Education, Science, Research and Sport of the Slovak Republic within the Research and Development Operational Programme for the project 'University Science Park of STU Bratislava', ITMS 26240220084, co-funded by the European Regional Development Fund.

\section{References}

[1] Howe K. J., Hand D. W., Crittenden J. C., Rhodes Trussell R., Tchobanoglous G. Principles of water treatment, Wiley, 2012.

[2] Pitter P. Hydrochemie, (in Slovak) $4^{\text {th }}$ Editions, Prague, University of Chemistry and Technology in Prague, 2009, pp. 592, ISBN: 978-80-7080-701-9.

[3] Holub M., Balintová M. Testing of various sorbents for copper sorption from acidic solutions, Pollack Periodica, Vol. 8, No. 2, 2013, pp. 47-54.

[4] Petriláková A., Bálintová M. Evaluation of sorbents efficiency on heavy metals like from acid mine drainage, Pollack Periodica, Vol. 6, No. 2, 2013, pp. 139-146.

[5] Marko I., Barloková D., Illavský J. Removal of bromates from drinking water with seven types of sorbent materials, Pollack Periodica, Vol. 13, No. 3, 2018, pp. 231-240.

[6] Huang W. J., Cheng Y. L. Effect of characteristics of activated carbon on removal of bromate, Separation and Purification Technology, Vol. 59, No. 1, 2008, pp. 101-107.

[7] Cabot Corporation, Norit granulated activated carbon GAC 1240, https://www. ulprospector.com/en/na/Food/Detail/17187/420404/Norit-GAC-1240, (last visited 15 September 2018).

[8] Cabot Corporation, Norit granulated activated carbon GAC $830 \mathrm{~W}$, http://www.cabotcorp. $\mathrm{com} / \sim /$ media/files/product-datasheets/datasheet-norit-gac-830w.pdf, (last visited 15 September 2018).

[9] Activated Carbon, Chemviron Carbon, Filtrasorb F400, (in Czech) http://www.jako.cz/ F400.pdf, (last visited 15 September 2018).

[10] Activated Carbon, Chemviron Carbon, Filtrasorb F100, (in Czech) http://www.jako.cz/ F100.pdf (last visited 15 September 2018).

[11] Bromate in drinking-water, WHO 2009, WHO/SDE/WSH/09.01/6.

[12] Decree of Ministry of Health of the Slovak Republic, No. 247/2017 Coll, (in Slovak), 2017.

[13] Guidelines for Drinking-water Quality, WHO, $3^{\text {rd }}$ Edition, Vol. 1, 2004.

[14] Manual for 850 Professional IC, 2.850.2030 - Anion MCS, Metrohm International Headquarters, Switzerland. 